\title{
Hysteroscopy in COVID 19 pandemic: safety concerns
}

\author{
Rakhi Rai, MIGS, MS, Kallol Kumar Roy, MD, Rinchen Zangmo, MD, Deepali Garg, MD \\ Department of Obstetrics and Gynecology, All India Institute of Medical Sciences, New Delhi, India
}

The coronavirus disease (COVID-19) pandemic is a global health crisis that negatively impacts the health infrastructure by diverting resources to manage this infection. The long-term impact on the health of patients due to a lack of appropriate medical care to avoid COVID-19 infection is already visible in the mortality rates of the general population. The presence of the severe acute respiratory syndrome coronavirus 2 in the female genital tract is not clear. Bubbles produced during hysteroscopy tend to cool down to the temperature of the distension medium and then dissolve. Hence, aerosols are not produced during hysteroscopy, which is usually performed in an office setting. If anesthesia is required, conscious sedation or regional anesthesia should preferably be used to reduce aerosol production. Hence, hysteroscopy is not an aerosol-generating procedure and the risk of COVID-19 infection is low; therefore, hysteroscopy should not be ruled out in emergencies.

Keywords: COVID-19; Hysteroscopy; Aerosols; Electrosurgery

\section{Introduction}

The coronavirus disease (COVID-19) pandemic is a global health crisis that negatively impacts the health infrastructure by diverting resources to manage this infection [1]. Nevertheless, we must cater to the needs of health emergencies. The long-term impact on the health of patients due to the lack of appropriate medical care to avoid COVID-19 infection is already visible in the mortality rates of the general population [2]. Hysteroscopy is not an aerosol-generating procedure; hence, the theoretical risk of COVID-19 infection is low, although the actual risk of contracting the infection is unknown [3].

Hysteroscopy is the gold standard for the diagnosis and treatment of various intrauterine conditions. It is usually performed in an office setting without anesthesia and is well tolerated [3]. Hysteroscopic procedures have the advantages of early ambulation, reduced morbidity, shorter hospital stays, and early return to work [4]. The concerns associated with hysteroscopy that can increase the risk of severe acute respiratory syndrome coronavirus 2 (SARS-CoV-2) infection include smoke production by use of electrosurgical devices, use of general anesthesia, and exposure to contaminated fluid from the pressurized uterine cavity [4].

\section{Safety concerns with hysteroscopy: does hysteroscopy increase the risk of COVID-19 infection?}

Hysteroscopy is not an aerosol-generating procedure; hence, the theoretical risk of COVID-19 infection is low, although the actual risk of contracting the infection is unknown. Bubbles produced using thermal devices during hysteroscopy (monopolar, bipolar, or laser) are rapidly cooled to the temperature of the liquid-distending medium and subsequently dissolve into it. Generated cell fragments and volatile gases at $\leq 37^{\circ} \mathrm{C}$ are suctioned through the outflow channel in a closed circuit with no aerosol generation, thereby minimizing the risk of viral transmission $[3,5]$.

Received: 2021.07.28. Revised: 2021.09.03. Accepted: 2021.10.05. Corresponding author: Rakhi Rai, MIGS, MS

Department of Obstetrics and Gynecology, All India Institute of Medical Sciences, Sri Aurobindo Marg, Ansari Nagar, New Delhi 110029, India

E-mail: drrakhi81@yahoo.co.in

https://orcid.org/0000-0002-8208-4126

Articles published in Obstet Gynecol Sci are open-access, distributed under the terms of the Creative Commons Attribution Non-Commercial License (http://creativecommons. org/licenses/by-nc/3.0/) which permits unrestricted non-commercial use, distribution, and reproduction in any medium, provided the original work is properly cited.

Copyright $\odot 2022$ Korean Society of Obstetrics and Gynecology 


\section{Obstetrics \& Gynecology Science}

Rakhi Rai, et al. Hysteroscopy in COVID 19 pandemic

Although studies have found SARS-CoV-2 in respiratory secretions, blood, urine, feces, and tears, its presence in the female genital tract is not clear [5]. SARS-CoV-2 was not found in vaginal secretions of pregnant and non-pregnant females in two studies [6,7], but a recent study detected a viral load in vaginal swabs by polymerase chain reaction in COVIDpositive patients [8]. Studies on previous epidemic infections with the Ebola/Zika virus shown their presence in the female genital tract of affected patients $[9,10]$.

Although the risk of SARS-CoV-2 transmission is low in hysteroscopy, certain precautions need to be taken to reduce transmission risk [1,3,5,11-14].

\section{General precautions}

- Pre-procedure screening of patients for COVID-19 with a questionnaire about symptoms and performing testing.

- Adequate distancing in the waiting area of the attendants should be available.

- Use of face masks and hand sanitizers should be encouraged.

- Personnel protective equipment should be used by healthcare workers.

- Minimize the number of personnel and limit the inflowoutflow of staff from the procedure room.

- Avoid the physical presence of trainees; train them through videos or online lectures instead.

- Provide enough time for decontamination of the procedure room if more than one case is posted on the same day.

\section{Specific precautions}

- Perform only those hysteroscopic procedures where delays can lead to adverse outcomes. Perform hysteroscopy for acute emergencies, such as cervical or cesarean scar ectopic pregnancies, heavy vaginal bleeding from submucosal fibroids or polyps, or potentially harmful conditions, such as retained products of conception or malignancies.

- If the patient is found to be positive for SARS-CoV-2 infection, postpone the procedure for 2 weeks.

- If hysteroscopy is urgently required in a COVID-positive patient, perform the procedure in COVID operation theatres with negative pressure and independent ventilation.

- Limit the number of attendants with the patient.

- Avoid multiple insertions and removals of the hysteroscope inside the uterine cavity.

- As far as possible, perform hysteroscopy in an office set- ting. If inpatient admission and anesthesia are required, conscious sedation or regional anesthesia should preferably be used.

- Prefer non-smoke-generating instruments, such as hysteroscopic scissors, graspers, or tissue retrieval systems. According to the joint statement by Royal College of Obstetricians and Gynaecologists, British Society of Gynaecological Endoscopy, British Gynaecological Cancer Society, hysteroscopy with the use of a tissue retrieval system or electrosurgery does not increase the risk of SARS-CoV-2 transmission as the virus has not been detected in the female genital tract.

- A suction device should be connected to the outflow sheath.

- Minimize the contamination with blood, genital tract secretions, feces, or urine during the procedure.

- Subsequent follow-up should be done by teleconsultation.

\section{Conclusion}

To conclude, although the risk of viral transmission is low during hysteroscopy, necessary precautions must be adopted. In case of emergency or potentially harmful conditions, appropriate medical care, and where required, a hysteroscopic procedure should be offered to the patient. Hysteroscopy should preferably be performed in an office setting, and if required, regional anesthesia or conscious sedation should be the first choice.

\section{Conflict of interest}

No potential conflict of interest relevant to this article was reported.

\section{Ethical approval}

This study does not require approval of the Institutional Review Board because no patient data is contained in this article. The study was performed in accordance with the principles of the Declaration of Helsinki. 


\section{Obstetrics \& Gynecology Science}

Vol. 65 , No. 1, 2022

\section{Patient consent}

Written informed consent and use of images from patient are not required for this publication as it does not involve patient data.

\section{Funding information}

None.

\section{References}

1. Roy KK, Rai R, Zangmo R, Kumari A, Noor N, Garg D. Laparoscopic gynecological surgery in COVID-19 pandemic. Obstet Gynecol Sci 2021;64:322-6.

2. Centre for Evidence Based Medicine. Tracking mortality over time [Internet]. Oxford (UK): CEBM; c2020 [cited 2021 Jul 28]. Available from: https://www.cebm.net/ covid-19/tracking-mortality-over-time/.

3. Carugno J, Di Spiezio Sardo A, Alonso L, Haimovich S, Campo R, De Angelis C, et al. COVID-19 pandemic. Impact on hysteroscopic procedures: a consensus statement from the global congress of hysteroscopy scientific committee. J Minim Invasive Gynecol 2020;27:988-92.

4. Alabi OC, Okohue JE, Adewole AA, Ikechebelu JI. Association of gynecological endoscopy surgeons of Nigeria (AGES) advisory on laparoscopic and hysteroscopic procedures during the COVID-19 pandemic. Niger J Clin Pract 2020;23:747-9.

5. Florez L, Carugno J. Hysteroscopy and COVID-19: have recommended techniques changed due to the pandemic? OBG Management September 2020;32:36-8.

6. Aslan MM, Uslu Yuvacı H, Köse O, Toptan H, Akdemir N, Köroğlu M, et al. SARS-CoV-2 is not present in the vaginal fluid of pregnant women with COVID-19. J Matern Fetal Neonatal Med 2020 Jul 16 [Epub]. https://doi.org/ 10.1080/14767058.2020.1793318.

7. Qiu L, Liu X, Xiao M, Xie J, Cao W, Liu Z, et al. SARSCoV-2 is not detectable in the vaginal fluid of wom- en with severe COVID-19 infection. Clin Infect Dis 2020;71:813-7.

8. Schwartz A, Yogev Y, Zilberman A, Alpern S, Many A, Yousovich $R$, et al. Detection of severe acute respiratory syndrome coronavirus 2 (SARS-CoV-2) in vaginal swabs of women with acute SARS-CoV-2 infection: a prospective study. BJOG 2021;128:97-100.

9. Rodriguez LL, De Roo A, Guimard Y, Trappier SG, Sanchez $A$, Bressler $D$, et al. Persistence and genetic stability of Ebola virus during the outbreak in Kikwit, Democratic Republic of the Congo, 1995. J Infect Dis 1999;179 Suppl 1:S170-6.

10. Prisant N, Bujan L, Benichou H, Hayot PH, Pavili L, Lurel S, et al. Zika virus in the female genital tract. Lancet Infect Dis 2016;16:1000-1.

11. Vitale SG, Carugno J, Riemma G, Farkas Z, Krasznai Z, Bacskó $G$, et al. The role of hysteroscopy during COVID-19 outbreak: safeguarding lives and saving resources. Int J Gynaecol Obstet 2020;150:256-8.

12. SASREG Endoscopy Sub-Committee. Guidance for Endoscopic Surgery during COVID-19 [Internet]. Durban (ZAF): SASREG; c2020 [cited $2021 \mathrm{Jul}$ 28]. Available from: https://sasreg.co.za/guidance-for-endoscopic-surgeryduring-covid-19-6-april-2020.

13. British Society for Gynaecological Endoscopy. Joint RCOG/BSGE guidance on gynaecological endoscopy during the COVID-19 pandemic [Internet]. London (UK): Royal College of Obstetricians and Gynaecologists; c2020 [cited $2021 \mathrm{Jul}$ 28]. Available from: https://www. rcog.org.uk/globalassets/documents/guidelines/202012-21-joint-rcog-bsge-gynaecological-endoscopy.pdf.

14. British Society for Gynaecological Endoscopy. Joint RCOG, BSGE and BGCS guidance for the management of abnormal uterine bleeding in the evolving coronavirus (COVID-19) pandemic [Internet]. London (UK): Royal College of Obstetricians and Gynaecologists; c2018 [cited 2021 Jul 28]. Available from: https://www.rcog.org. uk/globalassets/documents/guidelines/2020-05-21-jointrcog-bsge-bgcs-guidance-for-management-of-abnormal-uterine-bleeding-aub-in-the-evolving-coronaviruscovid-19-pandemic-updated-final-180520.pdf. 